\title{
Pulmonary Oedema: An Unusual Aetiology
}

\author{
Robert Smyth $^{\mathrm{a}}$ Michelle Canavan $^{\mathrm{b}}$ Marcia Bell ${ }^{\mathrm{b}}$ Robert Rutherford ${ }^{\mathrm{a}}$ \\ ${ }^{a}$ Respiratory Medicine, and ${ }^{b}$ General Internal Medicine, Galway University Hospitals, Galway, Ireland
}

\section{Key Words}

Negative pressure pulmonary oedema - Post-obstructive pulmonary oedema

A 47-year-old man had a sudden episode of collapse whilst eating followed by a generalised tonic-clonic seizure at a restaurant. Paramedics noted central cyanosis with an oxygen saturation of $70 \%$ on room air. Bag valve mask ventilation commenced and a food bolus was dislodged from the upper airway. The patient remained drowsy and hypoxic requiring 100\% oxygen. A chest radiograph (fig. 1) on admission revealed diffuse alveolar infiltrates. His clinical condition rapidly normalised over the next few hours, and a repeat chest radiograph at $48 \mathrm{~h}$ was normal. Transthoracic echocardiography, renal and brain imaging were normal.

The diagnosis is most consistent with negative pressure pulmonary oedema, also known as post-obstructive pulmonary oedema. This is caused by repeated, very forceful inspiratory manoeuvres against an obstructed upper airway (Müllers manoeuvre) with resultant highly negative intra-pleural pressures. This leads to increased pulmonary capillary pressures with transudation of fluid across the capillary membrane and alveolar oedema formation [1].

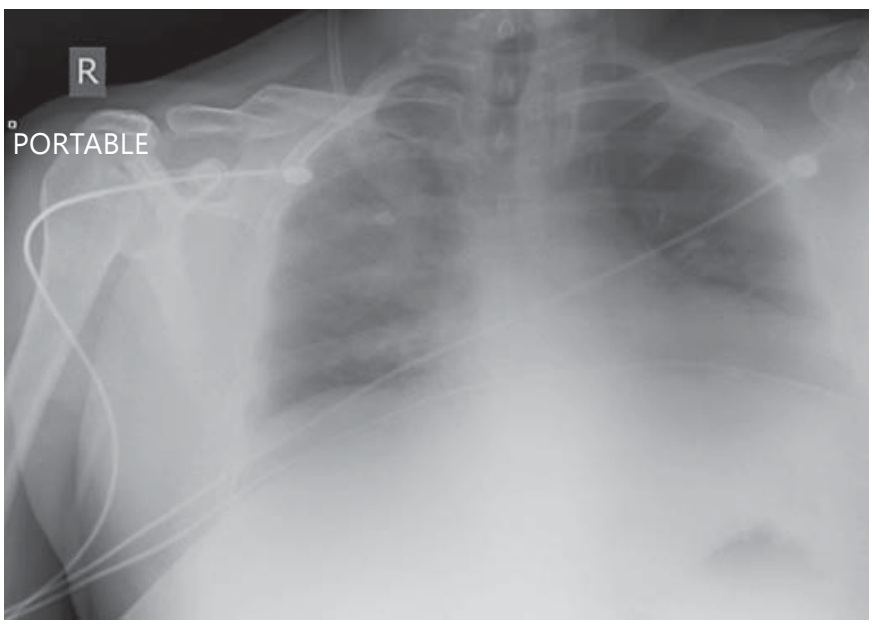

Fig. 1. Admission chest radiograph.

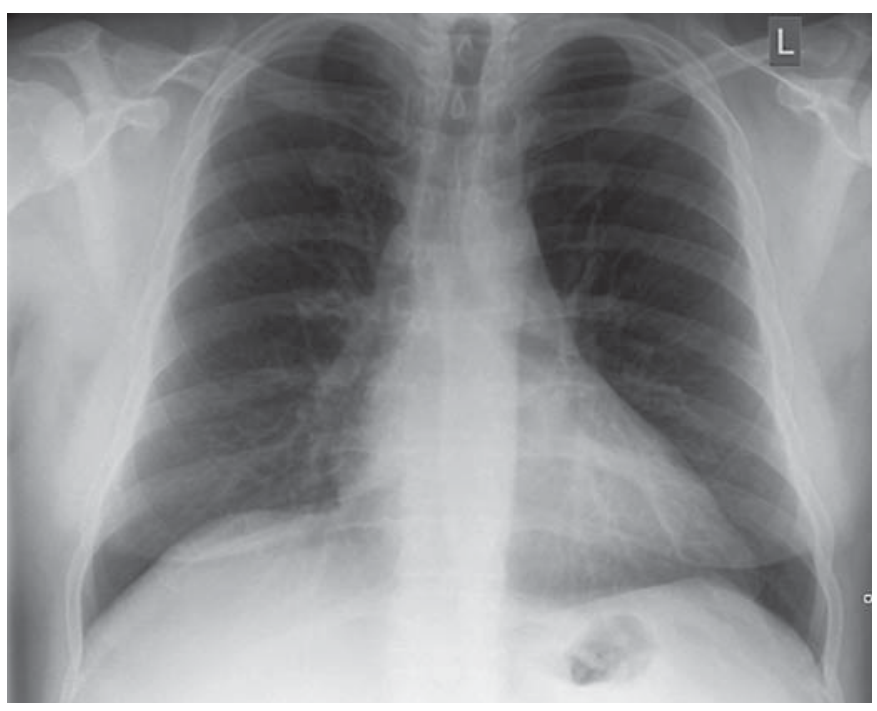

Dr. Robert Smyth

Respiratory Medicine, Galway University Hospitals Newcastle Rd

Galway (Ireland)

E-Mail robertsmyth23@gmail.com 
Negative pressure pulmonary oedema appears more common in healthy young individuals, occurring most often during emergence from anaesthesia [2], with the severity of pulmonary oedema seemingly related to the severity of airway obstruction. As well as laryngospasm, near strangulation or hanging and epiglotitis are also known causes. Recognition of the condition is important, as it is usually self-limiting, resolves within $24 \mathrm{~h}$ and is best managed by maintaining a patent upper airway, providing supplemental oxygen and the addition of non-invasive positive pressure ventilation. Initial positive endexpiratory pressure of between 5 and $10 \mathrm{~cm} \mathrm{H}_{2} \mathrm{O}$ is generally sufficient [3], improving the lung compliance, oxygenation and ventilation/perfusion mismatch. These measures will largely avoid the need for further, more aggressive, and potentially harmful interventions with the use of diuretics and steroids being particularly controversial [4].
This patient's presentation raises important differential diagnoses. Aspiration and anaphylaxis must be considered given the episode of choking, and the presence of seizure activity should alert the physician to neurogenic pulmonary oedema as a rare possibility.

References

1 Lemyze M, Mallat J: Understanding negative pressure pulmonary edema. Intensive Care Med 2014;40:1140-1143.

2 Udeshi A, Cantie SM, Pierre E: Postobstructive pulmonary edema. J Crit Care 2010;25: 508.e1-e5.

3 Stone DJ, Gal JJ: Airway management; in Miller RD (ed): Anesthesia, ed 3. New York, Churchill Livingstone, 1990, pp 1265-1292.

4 Chuang YC, Wang CH, Lin YS: Negative pressure pulmonary edema: report of three cases and review of the literature. Eur Arch Otorhinolaryngol 2007;264:1113-1116. 